\title{
Discussions with an Artist: Andres Caycedo \\ ("The New Bohemians"-- Art, Politics and Place) \\ Evelyn Lewiston
}

It had been two months or more since I had cause to fly to Cairns and meet with Andres Caycedo. His solo exhibition in December 2004 was entitled "Shopping Makes You Free". Having sought retail therapy to solve my love woes in the past, I was shocked to find that his was an exhibition which sardonically tore apart any notion of rationality for war. Here was brave, raw political comment.

Six months later we met for coffee. It was a cold, clammy August day. One dared hardly speak with an alternative political voice any more. The coffee shop banter was shallow and superficial; work politics, house renovations, and either kids or footy. Andres struck me as a man of slight build, Spanish-looking with dark curly hair and an olive complexion. One senses an easy going personality, unassuming and quiet on first meeting. Born in Colombia , Andres had lived in Australia for eight years. In retrospect on our first meeting, I seem to remember it was I who did most of the talking. Anxious to impart my ideas for a new book, I wanted Andres to agree to an interview.

But now it was December 2005 and I was driving out to Machans Beach. As the first of seven beaches north of Cairns, its title is hardly romantic, unlike Palm Cove, but I'd had a long relationship with this weatherboard community. In 1995 I had helped facilitate the development and later publishing of the community's history book. And there were lots of memories. The smells, colour and dust of the place were familiar. It was very hot $34^{\circ}$ with dripping humidity.

The fibro and wood cottage was shaded by a huge mango tree in the front garden. Ella the black kelpie greeted me at the gate. Andres was in typical North Queensland garb, a faded tshirt, cotton shorts and bare feet. We sat in the outer courtyard sipping iced lemonade. Ella cornered me as her new 'play' partner. She had a veritable treasure trove of balls and squeaky toys. The whole box was shortly confiscated by Andres and she slumped with a sigh to the floor. 
A yellow oriole pitched its high rising note intermittently as we chatted away about the heat... what else! Andres speaks with a low languid flowing tone of voice. He paused to reflect often, and has a habit of ending every third or fourth sentence with a querulous 'no..'? It's a colloquialism not dissimilar to the North Queensland 'eh?' meaning do you agree, and there's rarely an answer required.

Born in the Colombian capital, Bogota, Andres said he had a middle class upbringing. His father was a pilot for Avianca, the Colombian Airline, and his mother stayed at home bringing up the children. He went to Art School and then later moved to Chicago to widen his appreciation of contemporary art. "Art is the only thing I can make sense of doing in my life," Andres explained. "Probably about two years ago I started doing illustrations based on political commentary - it was a new thing for me."

I wondered what drove this change from 'apolitical' to vehemently 'anti-war'. "The war in Iraq , that was a turning point. As soon as this whole mess started, I thought to myself, ... okay, I have to see what's really happening, what's going on here, you know.

And I realised that somehow all through my life, I had been misled. Anyway so I started investigating, reading alternative media, watching the television commentary and comparing the different sources of information and the varying opinions.

You know I have lots of discussions with my brother, Eve. He's on the other side of politics I think. I'm more like you. You could say my views are more to the left although that's up for discussion no?"

I replied 'You mean as a term? Yes of course.'

"Precisely," Andres continued, "my brother lives in the Middle East . He is an oil engineer. And we argue by email and he tells me that I'm blind, that I'm carried away by my own prejudice, and well... that's probably true. I am."

I was keen to know how Andres had ended up living in Australia . "One of the reasons I came to Australia was for my partner. We had met in Oregon picking grapes. Gail is a wine maker, and yes a nurse as well. She comes from Tasmania which is where you're working now yes?" I replied ' That's right, in Launceston.' 
"I had some issues in Chicago . I had the use of a studio there and I started painting big canvases. I didn't have to pay rent, and it was a huge space, great great stuff.

And I worked as well selling wines in a Liquor store. I'd finish at 9pm at night, take a train to the studio and work. Then in the morning I would go back to my place to sleep and I liked that. I was very busy. I liked the rhythm of my life at that time. Not like now, I feel a bit lazy here in Cairns ."

'Maybe it's the weather, you can go 'troppo' here ...I think the heat induces a sort of creative inertia.'

"Maybe..." There was a long but comfortable pause, and I noticed it was very still. Although we weren't far from the beachfront, there was no breeze at all, just thick heat.

Andres continued "I met a lot of people in Chicago, a lot of artists. There is a very famous Art Institute and Museum and these places I used to visit all the time. There were huge halls with displays on the history of art, from the primitive to the contemporary. There was art from Korea , China, and there was even an Egyptian collection. I digress... anyway after three years in Chicago I had some problems with the law. A Colombian friend had rented me a room in a very nice house. It's difficult to find a place to live in Chicago and its expensive, and this friend offered me to stay for $\$ 200$ US a month. There were two other people in the house, but they were into the dirty business."

'Meaning what Andres?'

"Drug dealing .. but I thought well okay, I'll just live here. I won't mess with them. I am not into that sort of thing and besides, that house was very close to the studio you know. So it was fine, until one day there was a huge problem. These guys they used to make parties all the time. And the houses in this neighbourhood all have back porches. This porch of ours was on the second floor and it collapsed, yeh fell down, and the police came and made a raid, and they found weapons and drugs, and well ya ya.

That was one problem and then the other was we got arrested - handcuffed... for throwing stones on a factory roof, we were drunk. This was stuff I didn't need, so I went to Oregon to get away from it all. There I met Gail, yes we were picking grapes. 
And after the season was over, she came back to Australia and I returned to Chicago . There was another problem too.... I was illegal. I had a fake ID which meant I didn't do my tax and I lost a lot of money that way. I got tired of being illegal. I wanted to straighten out my life. I had met Gail...she was very nice ... she's still nice of course!"

We laughed. Andres was quite the romantic.

At that very moment, the metal gate clicked. Ella was already there wagging her tail and I met Gail. We all agreed some iced mango juice was the 'go' and sat around in the still humid heat, eating cherries and thin slices of brie. 'It's cherry season in Tassie, ' I remarked. "And raspberries too" said Gail. 'Raspberries of course, they are my favourite.'

We continued. "But yeh.. so I decided to come here to Australia and start from scratch you know. We communicated by snail mail. Back then I hated computers, and I still do in a way... sometimes. Now I hate television.

I got a visitor's visa, and then applied for a couple of extensions, then a temporary residency and then went straight to work. It was very easy from that point of view."

Andres went on to explain his first impressions of Melbourne and the Mornington Peninsula . He said he had always lived in large cities. "I started seeing less and less buildings and suddenly nothing, just paddocks and cows and I thought - What is this? I mean I like the countryside for a visit on a weekend maybe, but I was not used to living in it! But I kind of adapted to it."

After two years they moved to Melbourne because Andres was now able to work with a residency permit. "I haven't been lucky really finding jobs in Australia . I don't know why. ... Maybe because all the time they expect experienced people, even for cleaning toilets. I don't understand that. A lot of people say it's very easy to find jobs. I don't find it easy at all.

I gave up ... I thought I'm not going to waste my time on this.

I decided to spend my time doing art and that's when I bought the computer. I couldn't paint, the house we rented was too small. When the inspections come, everything has to be clean, impeccable you know, and I was fed up with that. So I thought buy the computer. I'm going to learn this thing. After all I had all the time in the world." 
I asked Andres if he had sold any paintings whilst in Melbourne . "No, I had sold a few paintings in Chicago and back in Colombia, but never have I had the idea of making a living out of art, never. Here I have the fortunate situation that Gail is working. She's been my patron really.

The thing is - I don't feel it's an obstacle for me - not having a cent in my pocket. Of course it's a bit hard sometimes, because everything costs. The advantage of using computers is that you don't need to buy canvases, expensive paints etc., everything fits into that little box and that's it."

It was soon apparent that after a year, they were fed up. Gail explained, Andres just said "Let's get out of here and go to the farthest place we can go to in Australia ." And they went all the way to the Kimberleys, to a little town called Wyndham. Andre added, "It's in the middle of nowhere, a post office, one fish \& chippery and one grocery shop. There's salt water but its very brownish, yeh on the edge of the Gulf of Cambridge and full of crocodiles."

"But the scenery was breathtaking, spectacular, amazing stuff..... very dry and rocky and like, ... ancient. Besides that I found it interesting. I'd never met an Aboriginal... a black man, and I was fascinated seeing black people and being able to observe their culture. Overall it was a fantastic place, one of the best experiences here in Australia . Gail was working there and we travelled together to Kalumburu and Oombulgurri and Warmun. I met a few ladies who were artists, Lilly and Rosie Karadada. Rosie is famous."

I was curious to know if their time in the Kimberleys had affected Andres' arts practice. "It was funny because, although I was in contact with all this wilderness, at the time I was more into computer programming. I had a laptop and used to take it everywhere."

Why did you leave?'

"We wanted a change ... it was too remote and we were planning to go back to Melbourne and figure out what we were going to do next but decided to go via the East Coast. Yeh we camped on the way, we drove first to Darwin, then Cairns . We liked Cairns but started heading south, and then thought no... let's go back."

The conversation drifted towards Andres' current poster work and I asked him what art had influenced his style of production. 
"Well I became interested by the posters produced during the Cultural Revolution in China , Mao Tse-tung. These artists were producing work which was very unconventional, also the posters coming out of Russia at the time, and North Korea. It was all Communist propaganda, I know. There is a saturation of political art back home but not as illustrative as you see in China and Russia . Cuba has a little bit of that. These art illustrators make images that are supposed to convey a sense of belonging, you know, that governments are 'in charge'. I liked the style. It's a contradiction."

"You asked me what has been the happiest time of my life thus far - I would have to say living here really, in Australia . Sure the trip Gail and I took to South America this year (2005) was great. We went in January and travelled to Colombia , Peru , Chile , Argentina and Bolivia . We didn't take pictures or do artwork, the purpose was to relax. The people are very humorous, it was a lot of fun."

I suggested to Andres that his art was then politically motivated by communism? "Look, I guess I am towards the left but that term 'left' it's not really appropriate I think? Because if you start thinking about social justice and poverty and the many problems we have in the world, including environmental problems... people say

'I know - you're a leftist .' Why? Why do people say that? Because I mean you care about the environment? The way other people are? You're concerned about the future of the world, the politics, why then are you a leftist?

On the other hand, you know its pretty appropriate the term 'right wing'. Right wing is somebody who believes in the force of law, the rule of capital, that sort of thing. That's appropriate."

'Well while we're talking politics, what about religion?'

"I don't feel any attachment to religion. I am interested in Buddhism in the philosophy of cause and effect. Everything is cause and effect after all. If you don't eat you die. If you live killing people, someone will shoot you down. If you live in a good way, respecting others and being friendly, you're going to have a

happy life. It's that simple." 
'Do you really believe that Andres?' "Yes I certainly believe that. America is going to pay dearly for what they have done. Since 2003, 250,000 Iraqis have been killed, that's not like taking a walk in the park. Actions don't simply float in a void and vanish. My grandmother used to say "In this world everybody pays, even the saints."

'And how would you describe the current political ideology in Australia ?' I asked. "It's Conservatism...governments basically shape the destiny of nations. For instance they promote the idea of free trade - globalisation. I was reading this Latin American writer Eduardo Galeano. He's been writing about politics in Uruguay for thirty years now, and he says that globalisation is done in the name of imperialism, same thing. Globalisation is another term, more friendly perhaps, more accepted, not as strong, but it's not a new concept it's imperialism - five hundred years old."

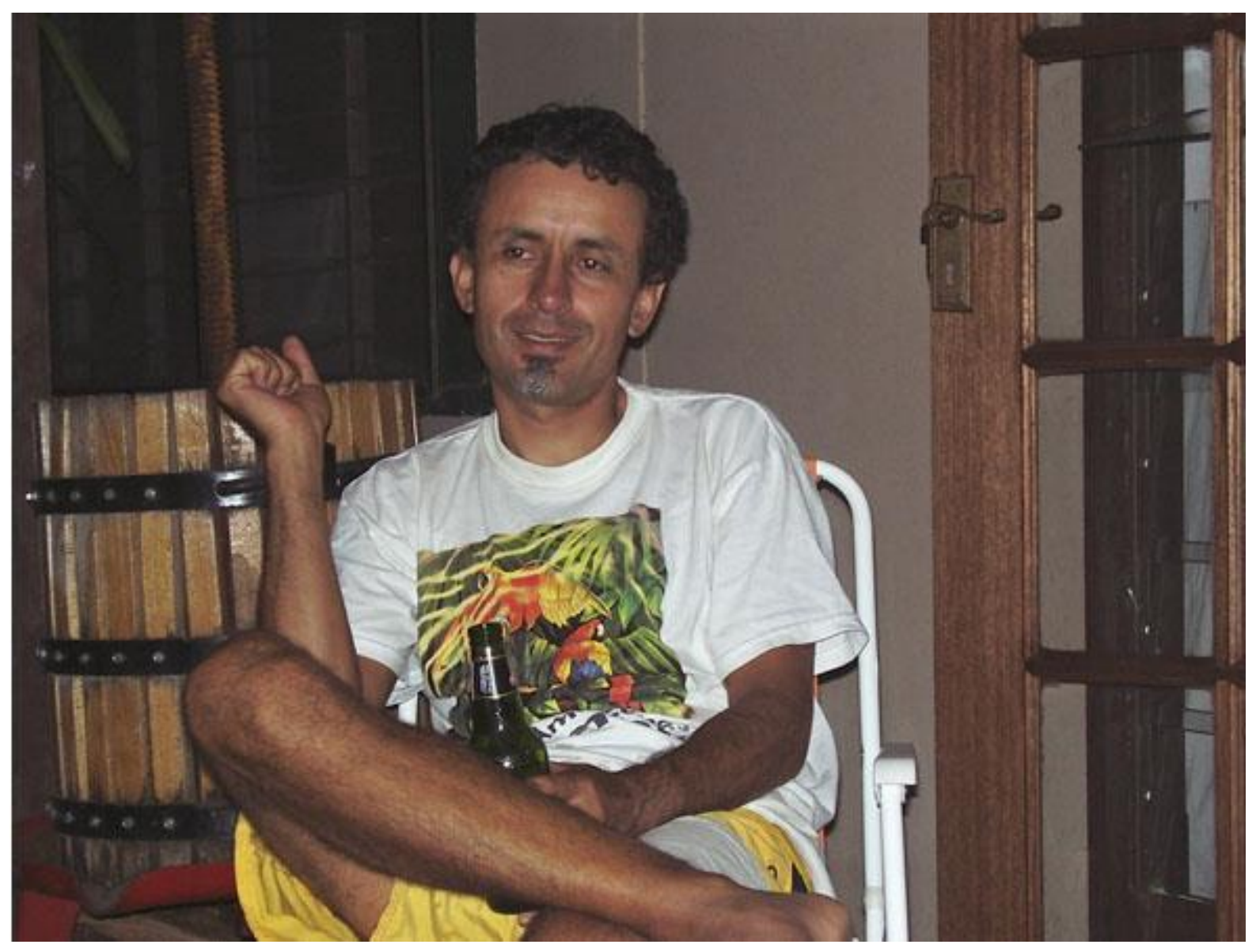

Andreas Caycedo Machan's Beach 
Asked whether he thought this conservatism affected artists and their work, Andres replied, "Well artists tend to be more open and liberal, less attached to conventional morals. An artist is supposed to question things, not accept them. There's always questioning in art, always."

In December 2005 The Australian Government introduced its contentious Anti-Terrorism Bill. Both NAVA (The National Association for the Visual Arts) and ALHR (Australian Lawyers for Human Rights) sought changes. The new laws were said to inhibit artists entitlement to exercise their human right to represent, discuss and critique ideas through their artwork or other forms of public or private expression.

"Some people are frightened about that certainly. (" The new Legislation? " I interjected.) Yes if you're a sympathiser, then you're a sympathiser of terror. If you talk against the Government you are a sympathiser of terror, there is no middle ground now in Australia, you either 'are' or you 'are not'."

"Take 'The Australian' which is a conservative newspaper, the editorial policy supports the Government with very few exceptions. If you have a cartoon critical of government they are like the fun part of the paper. I think such cartoons lack seriousness. That is not to say, that Australian cartoonists are not serious people."

So we agree such political comment is tokenistic ..."Yes meaningless, like the bombers saying, look we are balanced people!"

(Since this interview was recorded, twelve cartoonists in Denmark have gone underground as a result of global demonstrations against cartoon/s which illustrated Mohammed wearing a 'bomb-shaped' turban. A further twelve people have died in the firestorm of Muslim protest that followed.)

'Do you ever write to the 'Letters to the Editor" columns?'

"Yes I write to the Cairns Post. I wrote objecting about Japanese Whaling, and about the American sailors who come here to Cairns to have their holiday after killing people in Iraq . Yes I talk a very anti- American message and I am proud to be Anti-American. Yes of course $100 \%$. 


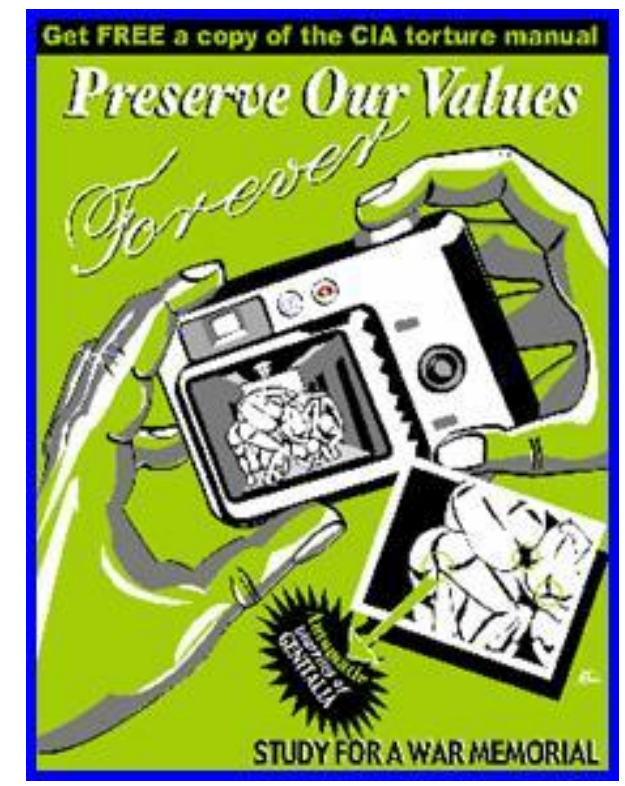

Listen Eve, the Americans portray themselves as 'the defenders of freedom' and all this is rubbish. They're not at all. And everybody knows that with Iraq . But not everyone knows for example, what's happened in Latin America with the Americans. Latin America is the back yard of the United States and they have had a strong presence in Latin American for 60-70 years' training the military, teaching techniques of torture, engineering assassinations, they're barbaric. The purpose of the whole situation is to control the flow of raw materials more particularly, oil,, copper and timber."

Andres continues to tell me that when he and Gail went to Peru and Bolivia it was to reconnect with the people there, and ask them what they thought about the political situation and their lives. The vast majority of people are very poor. "And I was spreading the message, an anti-American message of course. The people know exactly what is going on, the history of repression is going to be overturned. There is a trend to get rid of the American presence. Today (Monday 19 December 2005) is a very important date because there are elections in Bolivia right now and Evo Morales, an Indigenous leader is the favoured candidate."

I had read that Evo Morales was indeed successful and now too in Venezuela, Hugo Chavez was now President, Tabare Vazquex in Uruguay, Nestor Kirchner in Argentina, and Luba De Silva in Brazil . Andres was right. But it was more than just a trend. All these leaders are considered 'left wing'. I asked Andres exactly what they had in common.

"These leaders have been elected as a result of social discontent. In all these countries there is widespread misery and a 'well off' minority. The situation has been suppressed by military 
means, the real problems persist; crises in health, education, housing and a lack of clean water. The peasants have now organised themselves. The indigenous people who have been the victims of genocide and racial hatred - they organised themselves too. The dispossessed have found a voice, and together these people overthrew the corrupt governments... this is real democracy."

Andres became more animated as he made his point. Moving upright in the chair and using a fisted hand in his palm, he said

"You see I like politics. In the same sense as a psychologist is interested in the unconscious of any individual, politics is the conscience of society, how societies work."

These comments of course pleased me. As a Social Scientist, it makes a change to come across a person who not only advocates political change, but is not afraid to use his art as a method of dissent. I believe, like Andres, that politics is no longer the science of society but more a tool to pursue globalisation, the economic agenda. Can anyone recall voting for the removal of workers rights or limitations to our freedom of speech or expression?

Andres continued, "We need to think and act creatively and responsibly. Politics is not about pursuing economic agendas it is about democracy where decisions are made by the people. Politics is the only way to organise societies whereby we concern ourselves with the common good. For example, 'ads' on television which say - 'hey look its very important to look after the environment', instead of 'ads' about buying things, that would help."

So was there any positive aspect to Conservatism. "How can it be? Because ... I mean there's nothing positive. As I have said, cause and effect, it's a long process and things happen very slowly. So from this Conservatism, we will see the results in about 10-15 years."

'What would you say Andres is the worst aspect of this kind of Conservatism?'

"The violence that they are exporting. Weapons are used to kill people period. Shoot people in the head and splatter their brains on the ground. And that violence is the most monstrous thing to come out of those nations."

We talked about change. "Well when we went to South America , I took US dollars thinking this would be the dominant currency, and nobody wanted to change US dollars for me. It was 
pleasing to see. Euros was the currency people wanted to buy. So that's a symptom, it's a small example, agreed, again it's a slow process. But change....well there are many things that can be done."

Andres went on to say he thought everything would have to slow down eventually. I wish. "What is really curious," he said, "is that with so much cleverness, so much human greatness, there has not been a solution as yet for alternative fuels, rather than oil. We have to use to excess, excessive exploitation, excessive consumption."

Maybe we're all guilty I said. We're all driving round in cars. "True,. I mean, I'm no angel of course. I live very comfortably but I try to occupy as minimal a space as possible. I don't need a big house, we eat leftovers often. Of course you have to pay the bills, but I don't buy clothes. This watch I got for the job, my new job as a tour guide and driver." So obviously Andres had been without a watch until recently when he was offered a job in tourism.

"No, no watch, I'd never had a mobile phone either. I don't like depending on 'things'. Things' don't mean anything. You can lose everything for what? ... Even your loved ones. Nothing is here forever. So I try to detach myself from things, from ownership. When we go out we sometimes leave the door open, the window open, Australians I see them locking everything."

Lastly I asked Andres 'Do you think artists have a responsibility to inform people generally about the true nature of the political climate?'

"Well I don't know about responsibility, because it's a choice really. If you want to paint a palm tree and puppy dogs, that's fine with me. I don't judge you at all. I respect it. What I do think is that (for me) doing art has to have a function, a purpose. I got tired of painting abstract images on canvas. In a way it was gratifying, aesthetically. It was a catharsis if you like. But then I started thinking about the possibility of expressing 'dissent'.

Energised Andres leapt up "If the television says that industrial reforms are good not just for you (selfish bastard !) but for AUSTRALIA ! then just shut up and accept the changes because the television says so. The television says that we are in danger and we need the protection of the security state. The television says that we should keep buying things. The television says - look at these people, how they kiss and fuck. The television says look at 
these important men dressed in suits, they know better than you. The television says I'll make you happy. I'll entertain you."

'What of the future?' I asked.

"Well Gail tells me I'm a pessimist and probably I am. But I do think one can affect change." There was a pause. "What I think about Australians is that they shouldn't try to leave their footprint in world politics. They don't need that. Australians are very easy going, that's how they portray themselves and that's true, I see it."

'And what does culture mean to you?'

"Culture is fundamental. Culture is everything... from making a barbecue to the language we use, everything is culture.

When I go back to South America I reconnect with that culture. But I must confess I like meeting people from other parts of the world."

That evening we sat around in the darkening-pink tropical night, sharing a few beers and talking about people and places. I thought as I left, how easy the whole process had been, from the time I had arrived this morning; my clothes sticking to me, the cherries, cheese and fresh bruschetta for lunch, the laughter we shared and then the more serious questions about politics, art and society.

In the morning Gail would catch a plane to an aboriginal community to work. Andres would check his new watch and mobile, and drive tourists south to Josephine Falls. And I would catch the plane to Tasmania . Life is all a passage in motion.

Note: This research is part of a book of narratives being written and produced by Evelyne Lewis ton. The professional artists are based in Far North Queensland and North Queensland and their practice covers all genre but most particularly visual arts. The book is scheduled for publication online Easter 2007.

[an error occurred while processing this directive] 